\title{
Nature of Lowest Electron Transitions in Anionic Polymethine Dyes With Keto-Containing Terminal Groups
}

\section{A. P. Naumenko}

Kiivs'kij nacional'nij universitet imeni Tarasa Sevcenka

\section{I. Borisyuk}

Taras Shevchenko National University of Kyiv: Kiivs'kij nacional'nij universitet imeni Tarasa Sevcenka Olexiy Kachkovsky ( $\square$ kachkovskyalexey@gmail.com )

Institut bioorganicnoi himii ta naftohimii Nacional'na akademia nauk Ukraini https://orcid.org/00000003-3711-5154

\section{Yu. L. Slominskii}

Institute of Organic Chemistry National Academy of Sciences of Ukraine: Institut organicnoi himii Nacional'na akademia nauk Ukraini

\section{N. V. Obernikhina}

Bogomolets National Medical University: Natsional'nii meditsnii universitet imeni 0 O Bogomoltsa

\section{Original Research}

Keywords: anionic polymethine dyes, excitation fluorescence anisotropy spectra, quantum-chemical calculations, excited state, higher electron transitions

Posted Date: February 1st, 2021

DOl: https://doi.org/10.21203/rs.3.rs-164583/v1

License: (a) (1) This work is licensed under a Creative Commons Attribution 4.0 International License. Read Full License 


\title{
NATURE OF LOWEST ELECTRON TRANSITIONS IN ANIONIC POLYMETHINE DYES WITH KETO-CONTAINING TERMINAL GROUPS
}

\author{
A. P. Naumenko ${ }^{\text {a }}$ V.I.Borisyuk ${ }^{\text {a }}$, Yu. L. Slominskii ${ }^{\mathrm{b}}$, N. V. Obernikhina ${ }^{\mathrm{c}}$, O. D. Kachkovsky ${ }^{\mathrm{d}}{ }^{*}$ \\ ${ }^{a}$ Taras Shevchenko National University of Kyiv, Faculty of Physics, 60 Volodymirska Str., 03127, Kyiv, Ukraine \\ ${ }^{b}$ Institute of Organic Chemistry, NAS of Ukraine, 5 Murmanskaya str., Kiev, 02660, Ukraine \\ ${ }^{c}$ O.O. Bogomolets National Medical University, 13 T. Shevchenko Blvd., Kyiv, 01601, Ukraine \\ ${ }^{\mathrm{d}}$ V.P. Kukhar Institute of Bioorganic Chemistry and Petrochemistry, NAS of Ukraine, 1 Murmanska St., Kyiv, \\ 02094, Ukraine \\ *Corresponding author: kachkovskyalexey@gmail.com (O. Kachkovsky)
}

\begin{abstract}
The complex quantum-chemical and spectral study of the anionic polymethine dyes with the simplest symmetrical terminal groups and with different length polymethine chain is performed. It was shown that these dyes produce the specific molecular orbitals positioned nearly the energy gap and located only within the terminal groups. By investigation of the absorption spectra, it was established that the typical highly intensive longwawelength spectral band is observed which are bathochromically shifted upon lengthening of the open conjugated chain; this polymethine band is connected with the electron transition between the frontier levels of the opposite symmetry. In the contrast, the local MOs take part in so-called quasi-local electron transitions involved also one the frontier orbital. The local transitions have small dipole moments and hence they do practically not appear in the absorption spectra, however, the local transitions cause the appearance of the non-deep minima in the spectra of the fluorescence excitation anisotropy.
\end{abstract}

Keywords: anionic polymethine dyes, excitation fluorescence anisotropy spectra, quantumchemical calculations, excited state, higher electron transitions.

\section{Introduction}

The wide-known ionic (cationic and anionic) polymethine dyes (PMD) continue to be applied in numerous fields due to their exceptional spectral properties; they form a basis for the design of new effective materials connected with the light conversion [1-4]. Also, PMDs were found to be convenient objects for new theoretical conceptions and quantum-chemical models to develop [5-10]. Both cationic and anionic polymethine dyes have been established to distinguish, first at all, by a specific distribution of the total positive or negative charge within chromophore in the ground and excited state: it is not completely and uniformly delocalized along the conjugated chain of p-electrons, but it generates the wave of the alternated partial 
charges [11], independently on the sign of the total charge [5,7,9,11,13]. Also, it was demonstrated that going to first excited state is accompanied by the appreciable redistribution of the electron densities in the extensive polymethine chain, so that the densities increase at carbon atoms showing deficit of the electron densities in the ground state, while the electron densities decrease at the atoms bearing of the excessive of the densities in the ground state [2,12-14].

In the same time, the total charge is delocalized in the both the polymethine chain and two terminal groups; distribution of the charge between the different molecular fragments depends on the chemical constitution of the dyes. So, the cationic polymethine dyes contain the donor terminal groups which pull the excess of the electron densities from the both terminal residues to the polymethine chain $[12,15]$. In contrast, the acceptor terminal groups in the anionic dyes pull the electron density from the polymethine chain. It can be supposed that degree of the transferring of charge between the molecular fragments in cationic or anionic should be determined by the donor or acceptor strength of corresponding terminal groups. Vice-versa, the increasing or decreasing of the fragment charge within polymethine chain could estimate quantitatively the donor or acceptor strength of the terminal groups [4]. It is logical, that charge distribution between the fragments should change upon excitation. Traditionally, the redistribution of the charge upon the excitation in the PMDs were considered only for the first electron transition [16].

In the same time, it was shown that two lowest electron transitions in the polymethine dyes with the complex conjugated terminal groups, especially, with the comparatively short chain, should be treated as couple transitions so far as they involve two splitting levels and the same soliton level (or level of the charge) (see, for example, review [4] and refers therein). In the cationic dyes, two highest occupied levels are formed practically by the highest levels of both donor residues and hence could treated as donor levels. In the anionic polymethine dyes, in contrast, the first two excited states involve two lowest vacant levels which can be considered as acceptor levels.

Thus, the careful study of the excitation in the polymethine dyes and hence of charge redistribution requires the analysis of electron structure of the both first and second excited states; exactly electron transitions in these states determine the most important spectral properties: one- and two-photon absorption, fluorescence, fluorescence excitation anisotropy, non-linear optical characteristics, etc. [17,18].

This paper presents the results quantum-chemical and spectral investigation of the series of the symmetrical and unsymmetrical anionic dyes containing the terminal groups with the variable acceptor strength, the both first and second excited states taking into consideration. 


\section{Objects and Methodology}

Molecules. Structural formulas of the studied dyes are shown in Figure 1.<smiles>CC1(C)CC(=O)C(=CC=CC2=C([O-])CC(C)(C)CC2=O)C(=O)C1</smiles>

1a, 1b

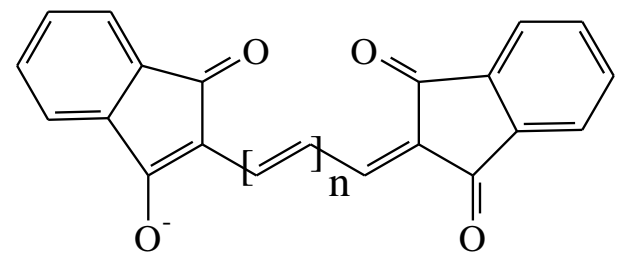

2a, 2b

Fig. 1. Formulae of dyes studied: a) $n=1$; b) $n=2$.

Two vinylogues with different length of the polymethine chain, $n=1$ and $n=2$, were investigate to estimate the effect of the lengthening of the chromophore. Both terminal groups contain the generic element: two conjugated diketon groups connected by non-conjugated bridge (compounds $\mathbf{1 a}, \mathbf{b})$ and connected by benzene cycle (compounds $\mathbf{2 a , b}$ ).

Synthetic procedure for the compounds $\mathbf{1 , 2}$ was described earlier [19,20].

UV-Vis absorption spectra were recorded on a Shimadzu UV-3100 spectrophotometer in, acetonitrile (spectral grade).

The anisotropy of fluorescence excitation spectra. Fluorescence excitation anisotropy measurements are performed using a CM 2203 spectrofluorometer (Solar, Belarus) in viscous solution (ethylene glycol) to reduce rotational reorientation and at low concentrations $\left(\mathrm{C} \square 10^{-6}\right.$ M) to avoid re-absorption of the fluorescence. The anisotropy, calculated by $r(\lambda)=\frac{I_{I I}(\lambda)-G \times I_{\perp}(\lambda)}{I_{I I}(\lambda)+G \times 2 \times I_{\perp}(\lambda)}$, is measured by setting the emission wavelength, typically near the fluorescence maximum, with a fixed polarization. Then, the fluorescence intensity is recorded as a function of excitation wavelength $\lambda$ at polarizations parallel $\left(I_{I I}(\lambda)\right)$ and perpendicular $\left(I_{\perp}(\lambda)\right)$ to the emission polarization. A G-factor expresses sensitivity ratio of detection system for perpendicular and parallel polarized light [21].

The quantum-chemical calculations were performed using (package Gaussian 03 [22]). The equilibrium geometry of dye molecules in the ground state was optimized by the nonempirical HF/6-31G(d,p) and DFT/6-31G(d,p)/CAM-B3LYP methods; the electron transition characteristics were calculated by the non-empirical (TD/DFT/6-31G(d,p)/CAM-B3LYP) method. It was found [8, 23, 24] that the calculations of the wavelengths of the electron transitions did not coincide perfectly with the experimental data (what is typical for this approach); however, it is enough to analyze correctly the nature of the electron transitions. 


\section{Results and Discussion}

\subsection{Geometry and electron structure of polymethine chromophore}

The performed calculations give that all four dye molecules, $\mathbf{1 a}, \mathbf{1 b}$ and $\mathbf{2 a}, \mathbf{2 b}$, are planar, excepting methyl groups, $\mathrm{CH}_{3}$, which are out molecular plane.

Bond lengths. According to Dahne's conception [2] of the ideal polymethine state, the lengths of the carbon-carbon bond in the polymethine dyes are maximum equalized, in contrast to the maximum charge alternation. In fact, the calculations give the appreciable alternation of the neighboring bonds in the chain of the dyes $\mathbf{1 a}, \mathbf{1} \mathbf{b}$ and $\mathbf{2 a}, \mathbf{2} \mathbf{b}$. It is convenient to estimate the bond length alternation by following parameter $\square 1_{\square}$ (Equation 1 ):

$$
\square 1_{\square}=\square 1_{\square}-1_{\square-1} \square
$$

where $1_{\square}$ is a length of $\square$-th bond.

The calculated function $\square 1_{\square}=f(\square)$ for the longer dyes $\mathbf{1 b}$ and $\mathbf{2} \mathbf{b}$ in both ground and first excited states are visually presented in Fig. 2.

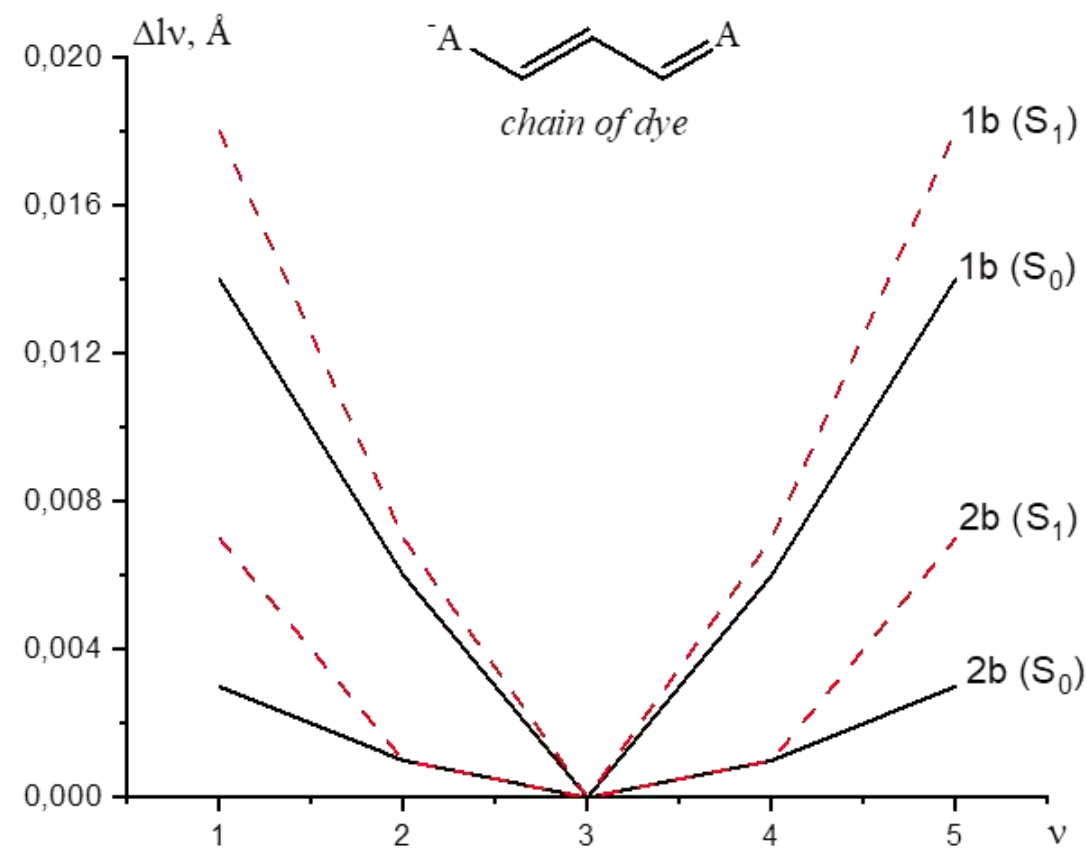

Fig. 2. Bond length alternation, $\square 1_{\square}$, in the chain of dyes $\mathbf{1 b}$ and $\mathbf{2 b}$, in ground $\left(\mathrm{S}_{0}\right)$ and excited $S_{1}$ states.

Firstly, the calculations give the negligible alternation of the bond lengths, particularly, in the chain middle of both dyes; however, the alternation degree increases somewhat in the excited state. Going from chain center to its both ends is accompanied by regular increasing of the parameter $\square 1_{\square}$. Also, the value $\square 1_{\square}$ for the bonds nearest to the terminal groups is appreciably sensitive to the acceptor strength (acidity) of residues (compare the dyes $\mathbf{1 b}$ and dye $2 \mathbf{b}$ in Fig. 2). 
Atomic charges. It was already noticed above that that total positive or negative charge in the ionic polymethine dyes does not delocalized uniformly in the chromophore, but generates the wave of the alternated electron densities at the carbon atoms along the polymethine chain $[11,15,25]$. Similarly, to the bond lengths, conveniently to analyze the dependence of the charge distribution on molecular constitution using the amplitude of the alternation, $\square \mathrm{q}_{\mathrm{a}}$, calculated by the following Equation 2:

$$
\square \mathrm{q}_{\mathrm{a}}=(-1)\left(\mathrm{q}_{\mathrm{c}+1}-\mathrm{q}_{\mathrm{\sigma}}\right),
$$

where $\mathrm{q}_{\square}$ is the electron density at $\square$-th atom.

The dependence of the calculated amplitude on the position of the atom in the chain, $\square \mathrm{q}_{\square}=\mathrm{f}(\square)$, for the longer dyes $\mathbf{1 b}$ and $\mathbf{2 b}$ (upon $\mathrm{n}=2$ ) in both states, ground $\mathrm{S}_{0}$ and excited $\mathrm{S}_{1}$, is pictured in Fig. 3.

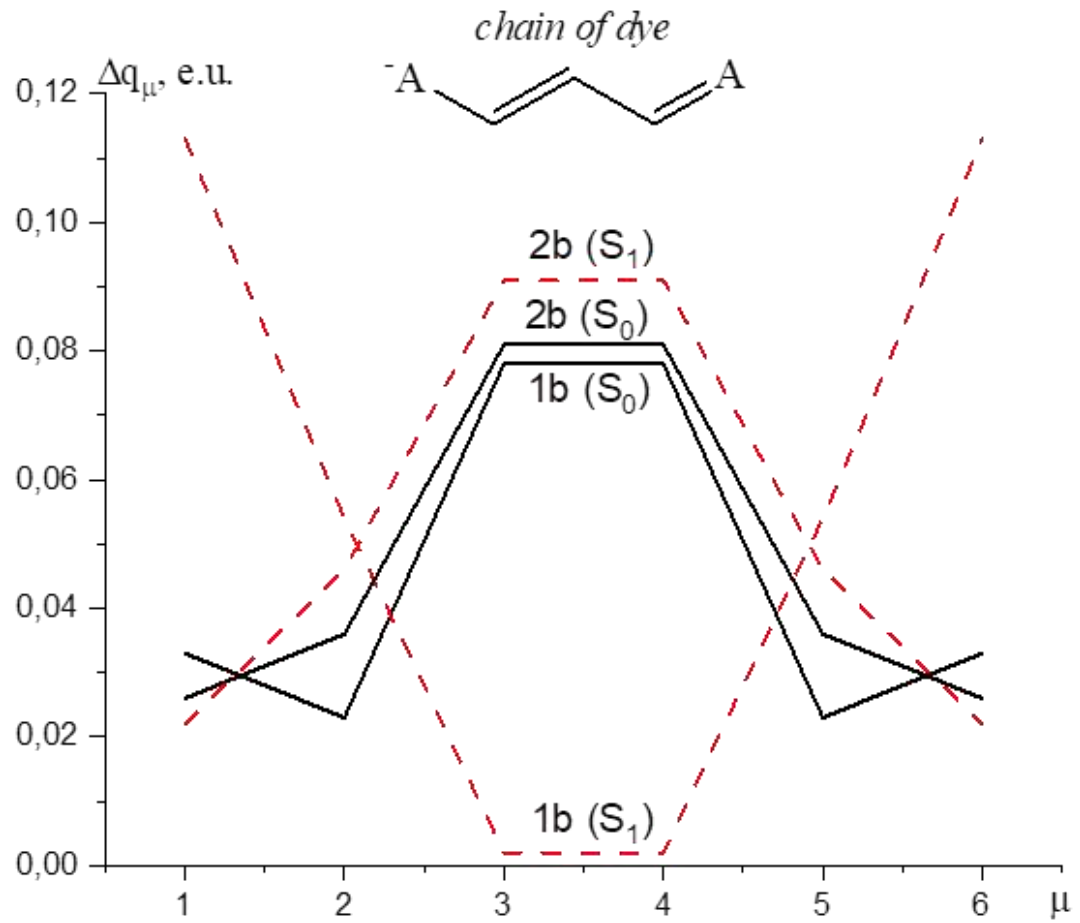

Fig. 3. Charge alternation, $\square q_{\mu}$, in the chain of dyes $\mathbf{1 b}$ and $\mathbf{2 b}$, in ground $\left(S_{0}\right)$ and excited $S_{1}$ states.

Figure 3 shows that the degree of the charge alternation, $\square \mathrm{q}_{\square}$, in the chain of the dyes $\mathbf{1 b}$ and $\mathbf{2 b}$ increases upon going from the terminal group to chain middle, with the exception of the excited state in the dye $\mathbf{2} \mathbf{b}$, when the parameter $\square \mathrm{q}_{\mathrm{v}}$ is minimal, whereas this parameter $\square \mathrm{q}_{0}$ decreases in the chain middle. In contrast to the dye $\mathbf{1 b}$, the alternation of the charges in the chain of other dyes regularly increases in middle of the chromophore, the values for the central atoms being practically insensitive to the acidity of the terminal groups: $\square \mathrm{q}_{\square}=0.080 \square 0.003$. 
And vice-versa, the minimum alternation degree follows from the calculation to be reached at both chain ends, the values $\square q$ is appreciably sensitive to the acceptor strength of terminal residues.

Shape of frontier and nearest molecular orbitals. Now, let us the shape of the frontier (highest occupied molecular orbital - HOMO and lowest unoccupied MO - LUMO) and nearest MOs which should involve in the lowest electron transitions and hence should be observed in the absorption spectrum in the visible region. Visually, these MOs are pictured in Fig. 4. 

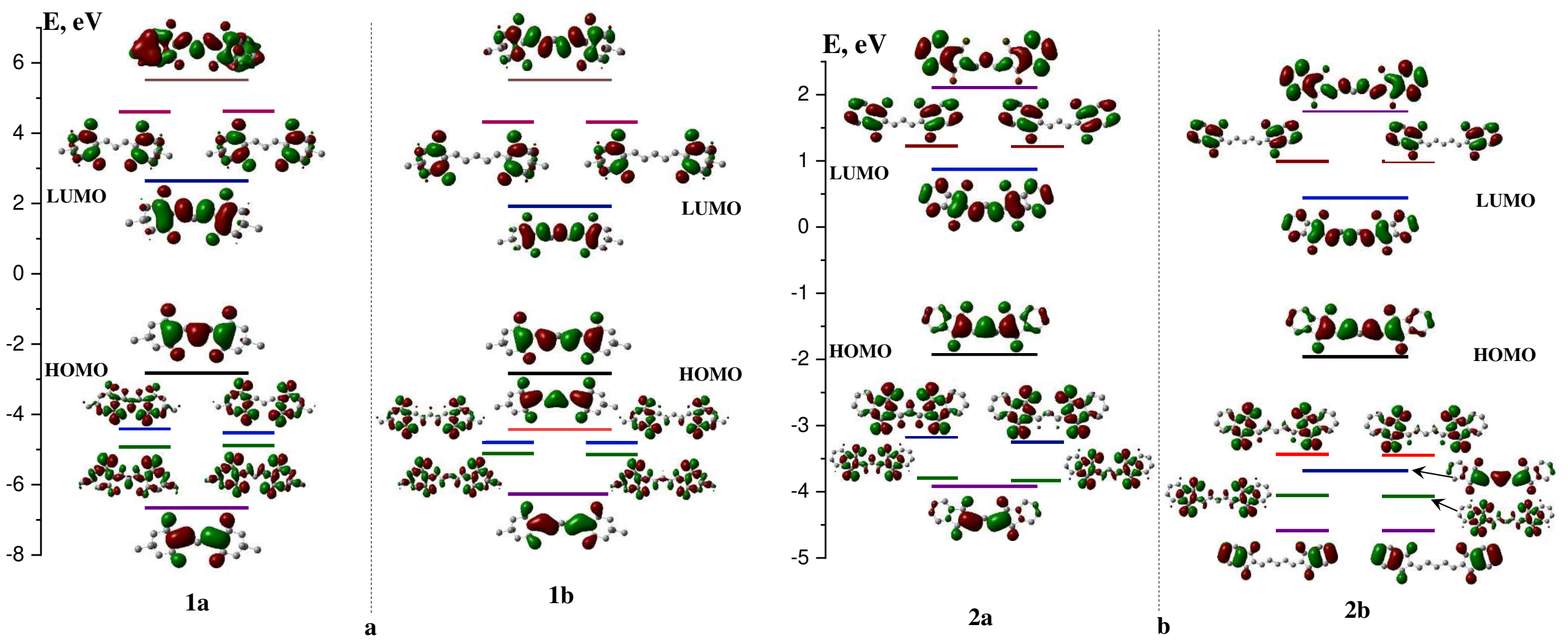

Fig. 4. Energies and shape of frontier and nearest MOs in $\mathbf{1 a , b}(\mathrm{a})$ and $\mathbf{2 a}, \mathbf{b}(\mathrm{b})$. 
Firstly, one can see that two types of $\square$-electron MOs appear nearly the electron gap and hence two types of the electron transitions can observe in the spectra. There are $\square$-orbitales delocalized in whole conjugated chromophore (delocalized MOs); so called local $\square-\mathrm{MOs,}$ located only in the branched terminal groups; additionally, there are n-MOs located at the onecoordinated oxygen atoms (so called the lone electron pair - LEP) in the both terminal groups with the corresponding electron levels.

Introducing of new vinylene group in the chain $(n=1 \square 2)$ results in the decreasing of the energy gap. Besides, the order of the arrangement of the delocalized and local orbital and LEP can be changed.

One can see that degenerated vacant LUMO+1 and LUMO+2 in the all dyes are exclusively localized within terminal groups and have their node at the carbon atoms connected with the polymethine chain; thus, the atoms of the chain do not take part in such orbitals. In was show earlier $[4,26]$ that the transitions involved the local MOs differ spectrally on the transitions between the totally delocalized orbitals, particularly, by their fluorescence excitation anisotropy.

Also, all dyes have two pairs occupied practically n-MOs located at two one-coordinated oxygen atoms (partly mixed with $\square$-MOs). The relative dispositions of the occupied $\square$ - and nlevels changes upon the chain lengthening. It is natural that such changes of nature of MOs nearly to the energy gap should influence of nature of the lowest electron transitions.

\subsection{Electron transitions}

Correspondingly, the nature of the lowest electron transitions could change depending on the nature of the involved MOs. The contributions of the individual MOs, or more exactly, the contributions single excited electron configurations $\square_{\mathrm{ijj}}$ (involved the $i$-MO and $j$-MO) in the function of the k-th excited state $\square_{k}$ are determined by an Equation 3 (in approximation of the configurational interaction):

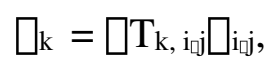

where $\mathrm{T}_{\mathrm{k}}, \mathrm{i}_{\mathrm{j}} \mathrm{j}$ is an expansion coefficient; summation runs over all configurations.

The calculated characteristics of some lowest transitions in both dyes $\mathbf{1 a}, \mathbf{1 b}$ are collected in Table 1, while the calculated data for dyes $\mathbf{2 a}, \mathbf{2} \mathbf{b}$ are presented in Table 2. 
Table 1. Calculated wavelengths ( $\square$ ), oscillator strength (f) and type of the electron transition of some lowest transitions in dyes $\mathbf{1 a}$ and $\mathbf{1 b .}$

\begin{tabular}{|c|c|c|c|c|c|}
\hline $\mathrm{n}$ & Transition & $\square, \mathrm{nm}$ & $\mathrm{f}$ & Type & Main configuration \\
\hline \multirow{8}{*}{1} & $S_{0} \square S_{1}$ & 383 & 1.134 & पि口* & $0.98 \square$ HOMO $\square$ LUMO> \\
\hline & $\mathrm{S}_{0} \square \mathrm{S}_{2}$ & 322 & 0.000 & $\mathrm{n} \square \square^{*}$ & $0.85 \square \mathrm{HOMO}-1 \square \mathrm{LUMO}>$ \\
\hline & $\mathrm{S}_{0} \square \mathrm{S}_{3}$ & 311 & 0.000 & $\mathrm{n} \square \square^{*}$ & $0.81 \square$ HOMO-2 $\square$ LUMO > \\
\hline & $\mathrm{S}_{0} \square \mathrm{S}_{4}$ & 296 & 0.000 & $\mathrm{n} \square \square^{*}$ & $0.76 \square$ HOMO-3 — LUMO> \\
\hline & $\mathrm{S}_{0} \square \mathrm{S}_{5}$ & 295 & 0.000 & $\mathrm{n} \square \square^{*}$ & $0.71 \square$ HOMO-4 L LUMO> \\
\hline & $\mathrm{S}_{0} \square \mathrm{S}_{6}$ & 242 & 0.180 & $\square \square \square^{*}$ Local & $0.90 \square \mathrm{HOMO} \square \mathrm{LUMO}+1>$ \\
\hline & $S_{0} \square S_{7}$ & 241 & 0.033 & $\square \square \square^{*}$ Local & $0.96 \square \mathrm{HOMO} \square \mathrm{LUMO}+2>$ \\
\hline & $\mathrm{S}_{0} \square \mathrm{S}_{8}$ & 236 & 0.049 & $\square \square \square^{*} \square$ & $0.82 \square \mathrm{HOMO}-5 \square$ LUMO> \\
\hline & & & & & \\
\hline \multirow{8}{*}{2} & $\mathrm{~S}_{0} \square \mathrm{S}_{1}$ & 440 & 1.710 & पि口* & $0.99 \square \mathrm{HOMO} \square \mathrm{LUMO}>$ \\
\hline & $\mathrm{S}_{0} \square \mathrm{S}_{2}$ & 322 & 0.000 & $\mathrm{n} \square \square^{*}$ & $0.85 \square$ HOMO-2 — LUMO> \\
\hline & $\mathrm{S}_{0} \square \mathrm{S}_{3}$ & 322 & 0.000 & $\mathrm{n} \square \square^{*}$ & $0.85 \square$ HOMO-1 $\square$ LUMO> \\
\hline & $\mathrm{S}_{0} \square \mathrm{S}_{4}$ & 303 & 0.000 & $\mathrm{n} \square \square^{*}$ & $0.80 \square \mathrm{HOMO}-4 \mathrm{~L}$ LUMO> \\
\hline & $\mathrm{S}_{0} \square \mathrm{S}_{5}$ & 302 & 0.000 & $\mathrm{n} \square \square^{*}$ & $0.77 \square$ HOMO-3 $\square$ LUMO> \\
\hline & $\mathrm{S}_{0} \square \mathrm{S}_{6}$ & 268 & 0.019 & 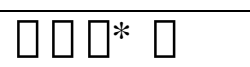 & $0.99 \square$ HOMO-1 $\square$ LUMO> \\
\hline & $\mathrm{S}_{0} \square \mathrm{S}_{7}$ & 247 & 0.185 & प૦०* Local & $0.91 \square \mathrm{HOMO} \square \mathrm{LUMO}+1>$ \\
\hline & $\mathrm{S}_{0} \square \mathrm{S}_{8}$ & 246 & 0.023 & 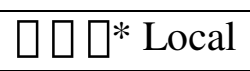 & $0.95 \square \mathrm{HOMO} \square \mathrm{LUMO}+2>$ \\
\hline
\end{tabular}

Table 2. Calculated wavelengths $(\square)$, oscillator strength (f) and type of the electron transition of some lowest transitions in dyes $\mathbf{2 a}$ and $\mathbf{2 b}$.

\begin{tabular}{|c|c|c|c|c|c|}
\hline $\mathrm{n}$ & Transition & $\overline{\mathrm{C}, \mathrm{nm}}$ & $\mathrm{f}$ & Type & Main configuration \\
\hline \multirow{7}{*}{1} & $\mathrm{~S}_{0} \square \mathrm{S}_{1}$ & 416 & 1.556 & पि口* & $0.99 \square$ HOMO $\square$ LUMO> \\
\hline & $S_{0} \square S_{2}$ & 378 & 0.026 & ૧૯口* Local & $0.96 \square \mathrm{HOMO} \square \mathrm{LUMO}+1>$ \\
\hline & $\mathrm{S}_{0} \square \mathrm{S}_{3}$ & 377 & 0.036 & ૧૯口* Local & $0.95 \square \mathrm{HOMO} \square \mathrm{LUMO}+2>$ \\
\hline & $\mathrm{S}_{0} \square \mathrm{S}_{4}$ & 349 & 0.000 & $\mathrm{n} \square \square^{*}$ Local & $\begin{array}{l}0.58 \square \text { HOMO-2 } \square \text { LUMO+1> } \\
-0.61 \square \text { HOMO-1 } \square \text { LUMO+2> }\end{array}$ \\
\hline & $\mathrm{S}_{0} \square \mathrm{S}_{5}$ & 348 & 0.000 & $\mathrm{n} \square \square^{*}$ Local & $\begin{array}{c}0.59 \square \mathrm{HOMO}-2 \square \mathrm{LUMO}+2> \\
-0.60 \square \mathrm{HOMO}-1 \square \mathrm{LUMO}+1>\end{array}$ \\
\hline & $\mathrm{S}_{0} \square \mathrm{S}_{6}$ & 329 & 0.000 & $\mathrm{n} \square \square^{*}$ & $0.70 \square$ HOMO-1 1 LUMO> \\
\hline & $\mathrm{S}_{0} \square \mathrm{S}_{7}$ & 326 & 0.005 & $\square \square \square^{*} \square$ & $0.92 \square$ HOMO-5 \ LUMO> \\
\hline & & & & & \\
\hline \multirow{6}{*}{2} & $\mathrm{~S}_{0} \square \mathrm{S}_{1}$ & 503 & 0.527 & 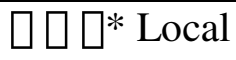 & $0.84 \square$ HOMO $\square$ LUMO+2> \\
\hline & $\mathrm{S}_{0} \square \mathrm{S}_{2}$ & 501 & 0.013 & $\square \square \square^{*}$ Local & $0.99 \square \mathrm{HOMO} \square$ LUMO+1> \\
\hline & $\mathrm{S}_{0} \square \mathrm{S}_{3}$ & 496 & 1.551 & पि口* & $0.85 \square \mathrm{HOMO} \square \mathrm{LUMO}>$ \\
\hline & $\mathrm{S}_{0} \square \mathrm{S}_{4}$ & 404 & 0.000 & $\mathrm{n} \square \square^{*}$ & $0.93 \square$ HOMO-1 $\square$ LUMO> \\
\hline & $\mathrm{S}_{0} \square \mathrm{S}_{5}$ & 403 & 0.000 & $\mathrm{n} \square \square^{*}$ & $0.93 \square$ HOMO-2 $\square$ LUMO> \\
\hline & $\mathrm{S}_{0} \square \mathrm{S}_{6}$ & 390 & 0.000 & $\begin{array}{l}\mathrm{n} \square \square^{*} \text { Local } \\
\mathrm{n} \square \square^{*} \text { Local }\end{array}$ & $\begin{array}{r}0.65 \square \mathrm{HOMO}-2 \square \mathrm{LUMO}+1> \\
-0.66 \square \mathrm{HOMO}-1 \square \mathrm{LUMO}+2>\end{array}$ \\
\hline
\end{tabular}




\begin{tabular}{|c|c|c|c|l|c|}
\hline \multirow{2}{*}{$\mathrm{S}_{0} \square \mathrm{S}_{7}$} & 389 & 0.000 & $\begin{array}{l}\mathrm{n} \square \square^{*} \text { Local } \\
\mathrm{n} \square \square^{*} \text { Local }\end{array}$ & $\begin{array}{c}0.65 \square \text { HOMO-2 } \\
-0.66 \text { LUMO+2> }\end{array}$ \\
\cline { 2 - 6 } & $\mathrm{S}_{0} \square \mathrm{S}_{8}$ & 364 & 0.001 & $\square \square^{*} \square$ & $0.93 \square$ HOMO-1 पLUMO+1> LUMO+3> \\
\hline
\end{tabular}

It follows from Table 1 and 2 that the first transition, $S_{0} \square S_{1}$, in three dyes is practically described by one configuration with single occupied frontier levels. Only, in dye $\mathbf{2 b}$, the transition involved the frontier levels is seen from Table 2 to be third; two first transitions involve the local LUMO+1 and LUMO+2. As far as frontier MOs are opposite symmetries $\left(\mathrm{C}_{2 \mathrm{v}}\right.$ symmetry group), then the first transition is anti-symmetric: $A_{1} \square B_{1}$, and hence it is polarized along polymethine chain (see, for example review [14] and refers therein). The calculated comparatively large transition dipole momentum should cause the high intensity of the longwavelength absorption band.

Going to the higher vinylogues, $\mathbf{1 a} \square \mathbf{1 b}$ and $2 \mathbf{a} \square \mathbf{2 b}$ is accompanied by the considerable decreasing of the energy of the first electron transition, so that longwavelength band in absorption spectrum should undergo the essential bathochromic shift (so called vinylogous shift).

\subsection{Spectral results}

Experimentally, the electron transitions in the polymethine dyes can be detected by their spectra: absorption and fluorescence and fluorescence excitation anisotropy. Figure 5 shows all three mentioned above spectra of the dyes studied. 

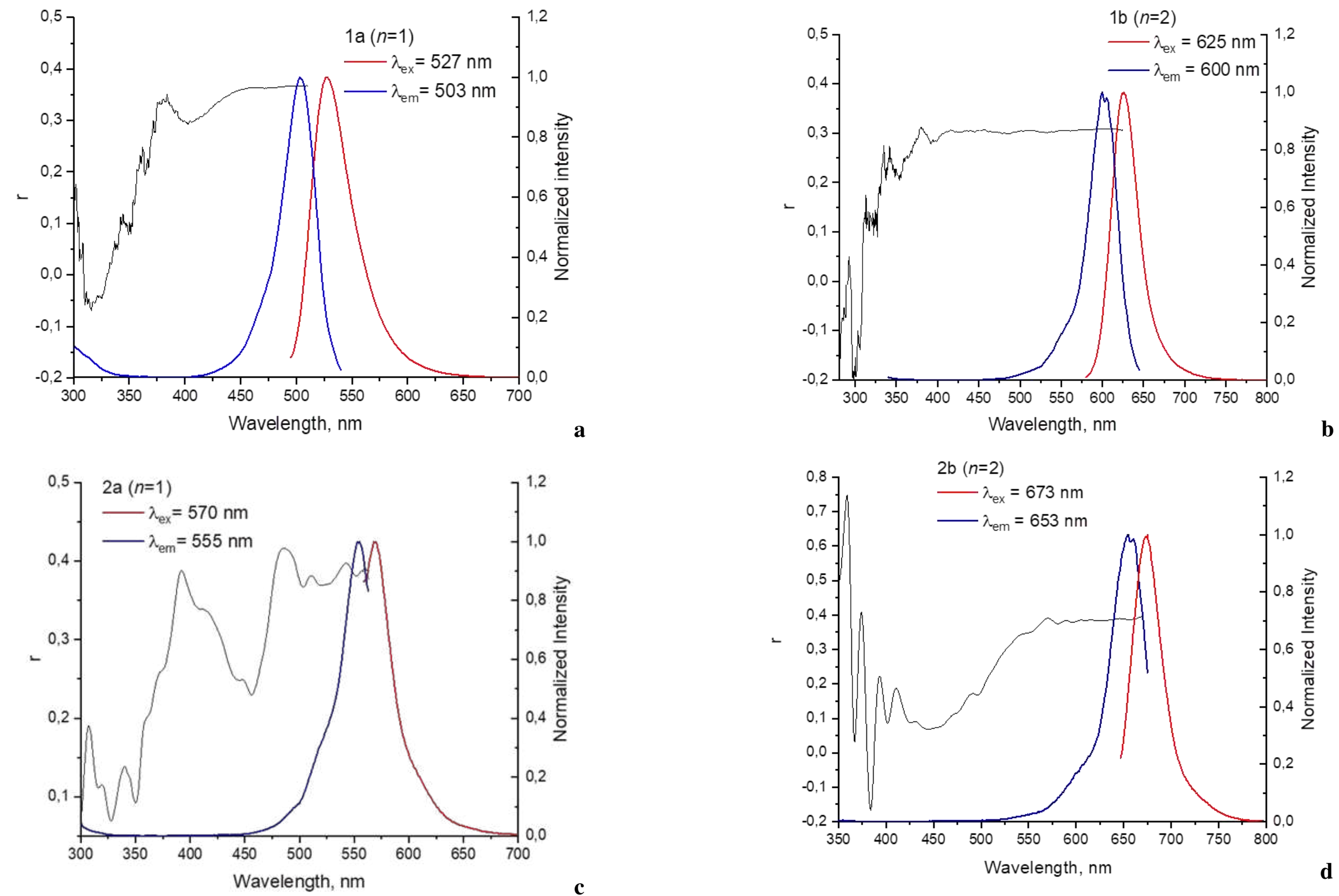

Fig. 5. Spectra of absorption (blue) fluorescence (red) and fluorescence excitation anisotropy (black) of the dyes 1a (a), 1b (b), 2a (c), 2b (d). 
One can see that these dyes show the comparative narrow and highly intensive band in the absorption spectra in the visible region. It is well-known that such a band is typical for the ionic polymethine dyes and is connected with the lowest electron transition involved practically only the frontier levels delocalized along the whole chromophore (see, for example, review [4] and refers therein). This agrees with the data in Table 1 discussed above. Also, the narrow band is observed in the fluorescence spectra with comparatively low Stock's shift; what is typical for the polymethine dyes [26].

However, there is an appreciable divergence between the calculated wavelength, $\lambda$ in Table 1, and experimental position of the band maximum, $\lambda_{\max }$, in the absorption spectra (Figure 5). This defect increases upon lengthening of the polymethine chromophore; the calculated vinylene shifts, $\lambda_{\max }(\mathrm{n}=2)-\lambda_{\max }(\mathrm{n}=1)$, proves to be regularly lower than the experimental value. Unfortunately, this is the typical imperfection of the TD DFT method upon calculation of the long linear conjugated systems (especially, their ions) analyzed in detail in the papers [23-25]. We could only optimistically expect that this method reflects correctly the nature of some lowest transitions, i.e. involved MOs, ratio and direction of the higher and first transition moments.

In the excitation fluorescence anisotropy, the relative deep minimum appears in the shorter region, nearly at 150-200 $\mathrm{nm}$ from the longwavelength absorption band maximum, when the parameter $r(\lambda)$ reaching extreme value. This spectrum is similar to the corresponding minimum in the spectra of the cationic polymethine dyes [27]. The similar minimum in the symmetrical cationic cyanine dyes corresponds to the second transition involved the one frontier MO (lowest unoccupied MO, i.e. LUMO) and next high occupied MO (HOMO-1); so far as both MOs are of the same symmetry, then this transition is polarized perpendicular to the first transition between MOs of the opposite symmetry [27]. In the anionic dye 1a perpendicular transition is seen from Table 1 to involve the HOMO-5 and LUMO totally delocalized in the whole main conjugated system. Then, we can propose that this transition is observed in the excitation fluorescence anisotropy spectrum as the deep minimum in the region $\square 320 \mathrm{~nm}$. Between these transitions (involved only the delocalized MOs), the calculations give some transitions of different nature: 4 transitions from 4 occupied n-MOs to the same vacant LUMO; as well as 2 transitions from the HOMO to the two degenerated local LUMO+1 and LUMO+2; apparently, they correspond to some non-deep minima in anisotropy spectrum in Fig. 5a.

In the longer dye $\mathbf{1 b}$, the next occupied delocalized orbital is seen from Figure HOMO-1, then the perpendicular transition is seen from Table 1 to involve the HOMO- 1 and LUMO totally delocalized. Considering the divergence between calculated and experimental data, we could 
propose that this transition mixed with the local transitions; apparently, it is a cause of the distortion of the shape of the anisotropy spectrum Fig. $5 \mathrm{~b}$.

The appreciable extending of the $\square$-system in the terminal groups in the dyes $\mathbf{2 a , \mathbf { b }}$ is accompanied by essential degreasing of the energy gap and hence by the shift of the longwavelegth spectral (both absorption and fluorescence) band connected with the first electron transitions. The calculations predict such shift $=33 \mathrm{~nm}$ upon $\mathrm{n}=1$ and $56 \mathrm{~nm}$ upon $\mathrm{n}=2$. The experimental measurements give the greater appreciably effect as one can see comparing the corresponding spectra in Fig. 5. So, going from dye 1a to dye 2a causes the shift of the longwavelength band in the absorption spectrum at $\square 55 \mathrm{~nm}$. Although the performed calculations give the two lowest electron transitions in dye $\mathbf{2 b}$ are local (see Table 2), however the typical polymethine spectral band is observed in the corresponding spectrum (Fig. 5d). Thus, the experimental effect of the extending of the $\square$-system of terminal groups is also $\square 55 \mathrm{~nm}$ (compare corresponding spectra in Fig. 5).

Of course, the similar shifting undergoes also the perpendicular $\left(\mathrm{A}_{1} \square \mathrm{A}_{1}\right)$ electron transition. The most clearly this spectral effect is observer for the short dyes. Comparing of calculated wavelengths of perpendicular $A_{1} \square A_{1}$ transitions corresponding dyes $\mathbf{1 a}$ and $\mathbf{2 a}$ (Tables 1 and Tables 2) gives $110 \mathrm{~nm}$, while the experimental effect is seen form Fig. 5a and 5c to be $\square 130 \mathrm{~nm}$. At the same time, similar estimation of the spectral effect for the local and $\mathrm{n} \square \square^{*}$ transitions are difficult because complexity of their spectral manifestations.

\section{Conclusion}

Thus, complex quantum-chemical and spectral study of the anionic polymethine dyes with the symmetrical terminal groups shows that the specific molecular orbitals appear nearly the energy gap located only within the terminal groups. In the absorption spectra, the typical high intensive longwawelength spectral band is observed which is bathochromically shifted upon lengthening of the open conjugated chain; this band is connected with the electron transition between the frontier levels of the opposite symmetry. At the same time, the local MOs produce so-called quasi-local electron transitions involved one of the local MO and one the frontier orbital. Because of the small dipole moments, the local transitions do practically not appear in the absorption spectra, however, they cause the appearance of the non-deep minima in the spectra of the fluorescence excitation anisotropy.

\section{Declarations}

Ethics approval: N/A 
Consent to participate: all authors agree to consult to participate in the study.

Consent for publication: all authors agree to the publication of materials.

\section{Authors' contributions:}

\begin{tabular}{|l|l|}
\hline Author names & Contributions \\
\hline O. D. Kachkovsky & $\begin{array}{l}\text { Ideas; formulation of overarching research } \\
\text { goals and aims, development of methodology }\end{array}$ \\
\hline A. P. Naumenko & $\begin{array}{l}\text { Ideas; management and coordination } \\
\text { responsibility for the research activity } \\
\text { planning and execution, analysis of results } \\
\text { anisotroscopy }\end{array}$ \\
\hline N. V. Obernikhina & $\begin{array}{l}\text { Formulation of research goals and aims, } \\
\text { application of statistical, mathematical, } \\
\text { computational, or other formal techniques to } \\
\text { analyze study data }\end{array}$ \\
\hline Yu. L. Slominskii & $\begin{array}{l}\text { Evolution of research goals and aims, } \\
\text { application of formal techniques to analyze } \\
\text { and synthesize study data }\end{array}$ \\
\hline V. I. Borisyuk & $\begin{array}{l}\text { Conducting spectral measurements and } \\
\text { investigation process, preparation, creation, } \\
\text { and presentation of the published work }\end{array}$ \\
\hline
\end{tabular}

Funding: no funding was received.

Competing interests: the authors declare that they have no known competing financial interests or personal relationships that could have appeared to influence the work reported in this paper.

Availability of data and material: N/A

\section{References}

[1] A. Mishra, R.K. Behera, P.K. Behera, B.K. Mishra, G.B. Behera, Chem. Rev., 2000, 100, 1973. DOI: $10.1021 / \mathrm{cr} 990402 \mathrm{t}$

[2] G. Bach, S. Daehne, Cyanine dyes and related compounds, in ROOD'S Chemistry of Carbon Compounds, 2nd suppl. to 2nd edn., vol. IVB, chapter 15, Heterocyclic Compounds, ed. by, M. Sainsbury (Elsevier Science, Amsterdam, 1997), pp. 383-481. DOI: 10.1016/B978-044453347$0.50165-8$

[3] S.R. Marder, Chem. Commun., 2006, 2, 131. DOI: 10.1039/B512646K 
[4] J. L. Bricks, A. D. Kachkovskii, Yu. L. Slominskii, A. O. Gerasov, S. V. Popov, Dyes Pigm., 2015, 121, 238. DOI: 10.1016/j.dyepig.2015.05.016

[5] A. B. Ryabitzki, A. D. Kachkovskii, O. V. Przhonska, J. Mol. Struct.: THEOCHEM, 2007, 802(1-3), 75. DOI: 10.1016/j.theochem.2006.09.004

[6] J. S. Craw, J. R. Reimers, G. B. Bacskay, A. T. Wong, N.S. Hush, Chem. Phys., 1992, 167, 77. DOI: 0.1016/0301-0104(92)80024-P

[7] J.S. Craw, J.R. Reimers, G.B. Bacskay, A.T. Wong, N.S. Hush. Chem. Phys., 1992, 167, 101. DOI: 10.1016/0301-0104(92)80025-Q

[8] J. Fabian, Dyes Pigm., 2010, 84, 36. DOI: 10.1016/j.dyepig.2009.06.008

[9] O.S. Nychyporenko, O.P. Melnyk, O.O. Viniychuk, T.M. Pinchuk-Rugal, V.A. Brusentsov, E.L. Pavlenko, O.P. Dmytrenko, N.P. Kulish, O.D. Kachkovsky, Intern. J. Quant. Chem., 2014, 114, 416. DOI: 10.1002/qua.24585

[10] I. G. Davydenko, Y. L. Slominskiy, N. V. Obernikhina, A. D. Kachkovsky, A. I. Tolmachev, ChemistrySelect, 2020, 5(2), 674. DOI: 10.1002/slct.201904086

[11] K. O. Maiko, I. M. Dmitruk, N. V. Obernikhina, A. D. Kachkovsky, Monatsh. Chem., 2020, 151(4), 559. DOI: 10.1007/s00706-020-02572-y

[12] A. O. Gerasov, M. P. Shandura, Yu. P. Kovtun, A. D. Kachkovsky, J. Phys. Org. Chem., 2008, 21(5), 419. DOI: 10.1002/poc.1368

[13] O. V. Przhonska, H. Hu, S. Webster, J. L. Bricks, A. A. Viniychuk, A. D. Kachkovski, Yu.

L. Slominsky, Chem. Phys., 2013, 411, 17. DOI: 10.1016/j.chemphys.2012.11.017

[14] A. D. Kachkovsky, Russ. Chem. Rev. 1997, 66(8), 647.

DOI: 10.1070/RC1997v066n08ABEH000274

[15] A. Kachkovsky, N. Obernikhina, Ya. Prostota, A. Naumenko, D. Melnyk, V. Yashchuk, J. Mol. Struct., 2018, 1154, 606. DOI: 10.1016/j.molstruc.2017.10.051

[16] O. Chernega, S. Levchenko, A. Ryabitskii, A. Gerasov, O. Kachkovskii, Yu. Yagupolskii, Dyes Pigm, 2015, 123, 176. DOI: 10.1016/j.dyepig.2015.07.037

[17] O. V. Przhonska, S. Webster, L. A. Padilha, H. Hu, A. D. Kachkovski, D. J. Hagan, E. W. Van Stryland. Two-photon absorption in near-IR conjugated molecules: design strategy and structure-property relations. Chapter to the Book "Advanced Fluorescence Reporters in Chemistry and Biology I, Springer Ser. Fluorescence”, Springer-Verlag, Berlin-Heidelberg, 2010, 8, 105. DOI: 10.1007/978-3-642-04702-2_4

[18] Ya. Gayvoronsky, A.V. Uklein, A.O. Gerasov, V.V. Garashchenko, Yu.P. Kovtun, M.P. Shandura, O.D. Kachkovsky, J. Mol. Struct.,2013, 1045, 191.

DOI: 10.1016/j.molstruc.2013.03.061 
[19] Yu.L. Slominskiy, I.D. Radchenko. Chem. Heterocycl. Compd., 1974, 5, 711-715.

[20] Zh. A. Krasnaya, T. S. Stytsenko, D. G. Gusev, E. P. Prokof'ev, Izv. Akad. Nauk SSSR, Ser. Khim., 1986, 1596-1602.

[21] J. R. Lackowicz, Principles of Fluorescence Spectroscopy; $3^{\text {rd }}$ edition, Springer: US, 2006. DOI: $10.1007 / \mathrm{s} 00216-007-1822-\mathrm{x}$

[22] M.J. Frisch, G.W. Trucks, H.B. Schlegel, et al., GAUSSIAN03 Revision B.05, Pittsburgh, PA, 2003.

[23] S. Karaca, N. Elmaci, Comput Theor Chem, 2011, 964, 160.

DOI: 10.1016/j.comptc.2010.12.016

[24] D. Jacquemin, Ya. Zhao, R. Valero, C. Adamo, I. Ciofini, D. G. Truhlar, J. Chem. Theory Comput., 2012, 8, 1255. DOI: 10.1021/ct200721d

[25] A. V. Kulinich, N. A. Derevyanko, E. K. Mikitenko, A. A. Ishchenko, Phys. Org. Chem., 2010, 24(8), 732. DOI: 10.1002/poc.1821

[26] J.Fu, L. A. Padilha, D. J. Hagan, E. W. Van Stryland, O. V. Przhonska, M. V. Bondar, Yu. L. Slominsky, A. D. Kachkovski, J. Opt. Soc. Am., 2007, 24(1), 56.

DOI: $10.1364 / J O S A B .24 .000056$

[27] O.O. Viniychuk, S.M. Levchenko, O.V. Przhonska, O.D. Kachkovsky, Yu.L. Bricks, M.O. Kudinova, Yu.P. Kovtun, Ye.M. Poronik, M.P. Shandura, O.I. Tolmachev, J. Molc. Struct., 2014, 1060, 30. DOI: 10.1016/j.molstruc.2013.12.038 
Figures

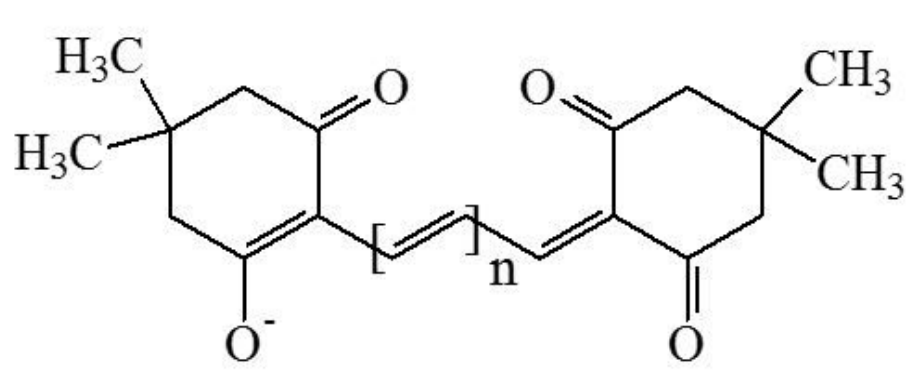

1a, 1 b

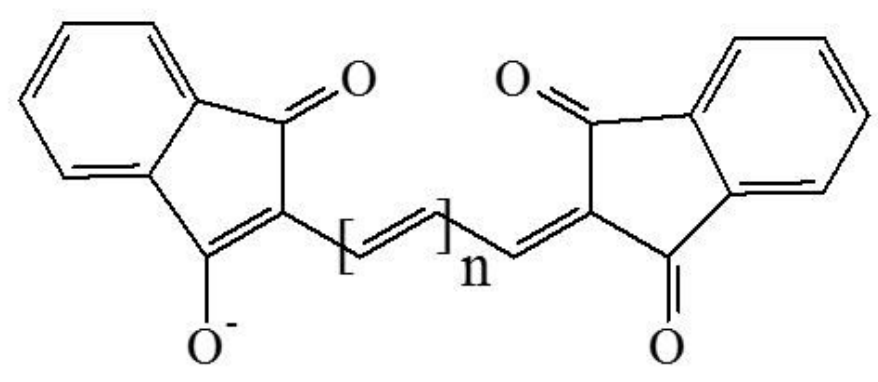

2a, 2 b

Figure 1

Formulae of dyes studied: a) $n=1 ; b) n=2$.

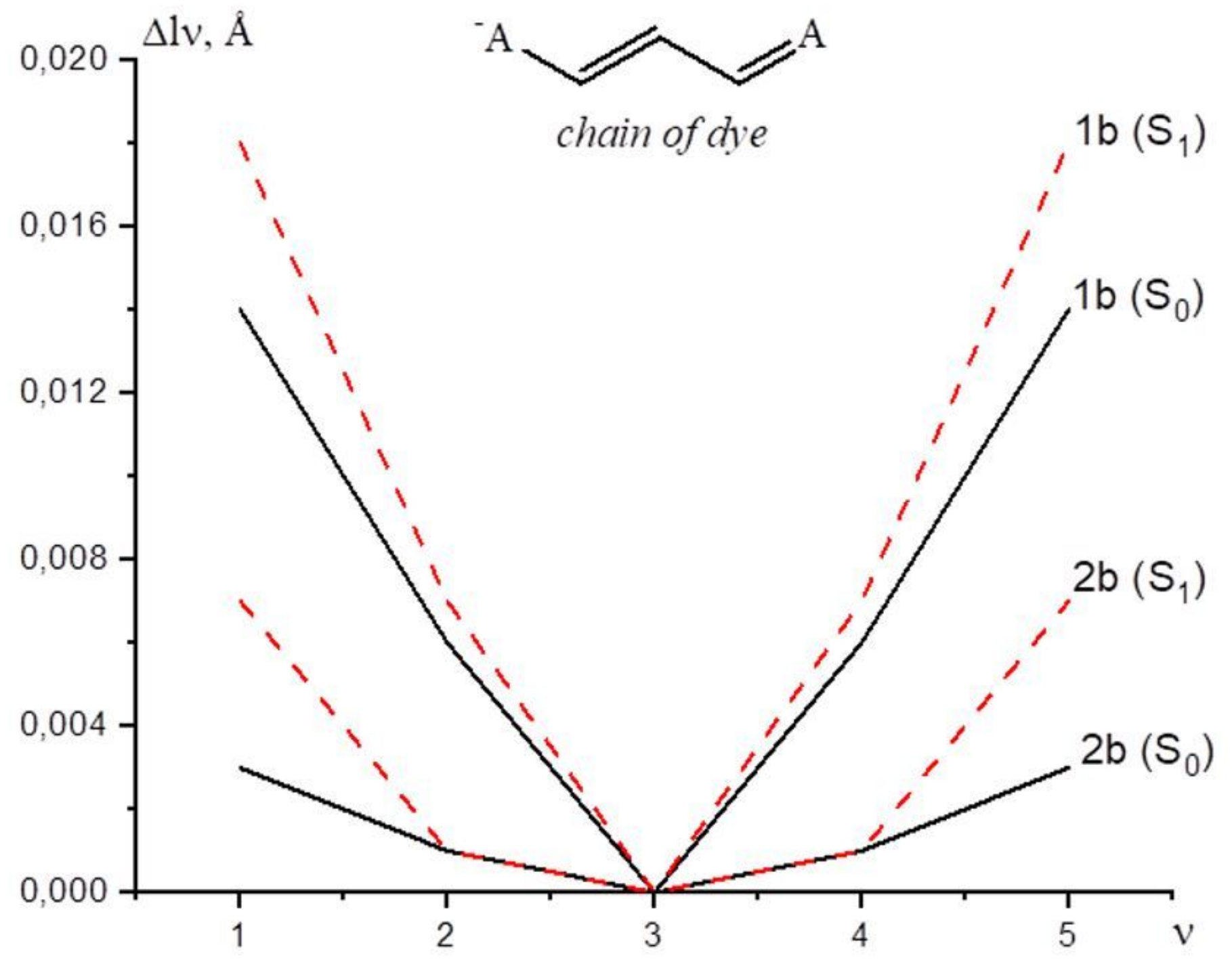


Figure 2

Bond length alternation, $\Delta \mathrm{lo}$, in the chain of dyes $1 \mathrm{~b}$ and $2 \mathrm{~b}$, in ground (S0) and excited S1 states.

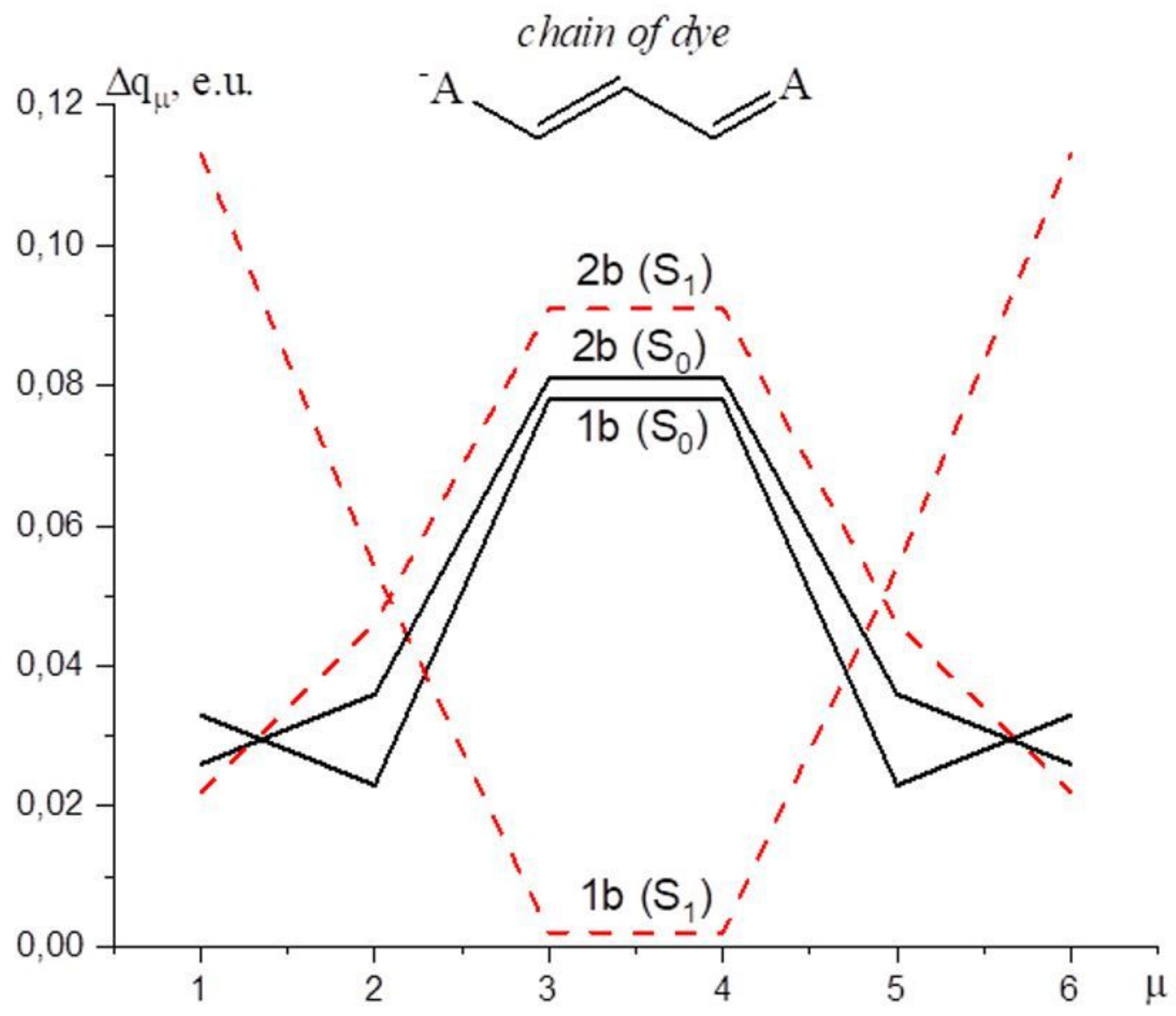

Figure 3

Charge alternation, $\Delta q \mu$, in the chain of dyes $1 b$ and $2 b$, in ground (S0) and excited $S 1$ states. 

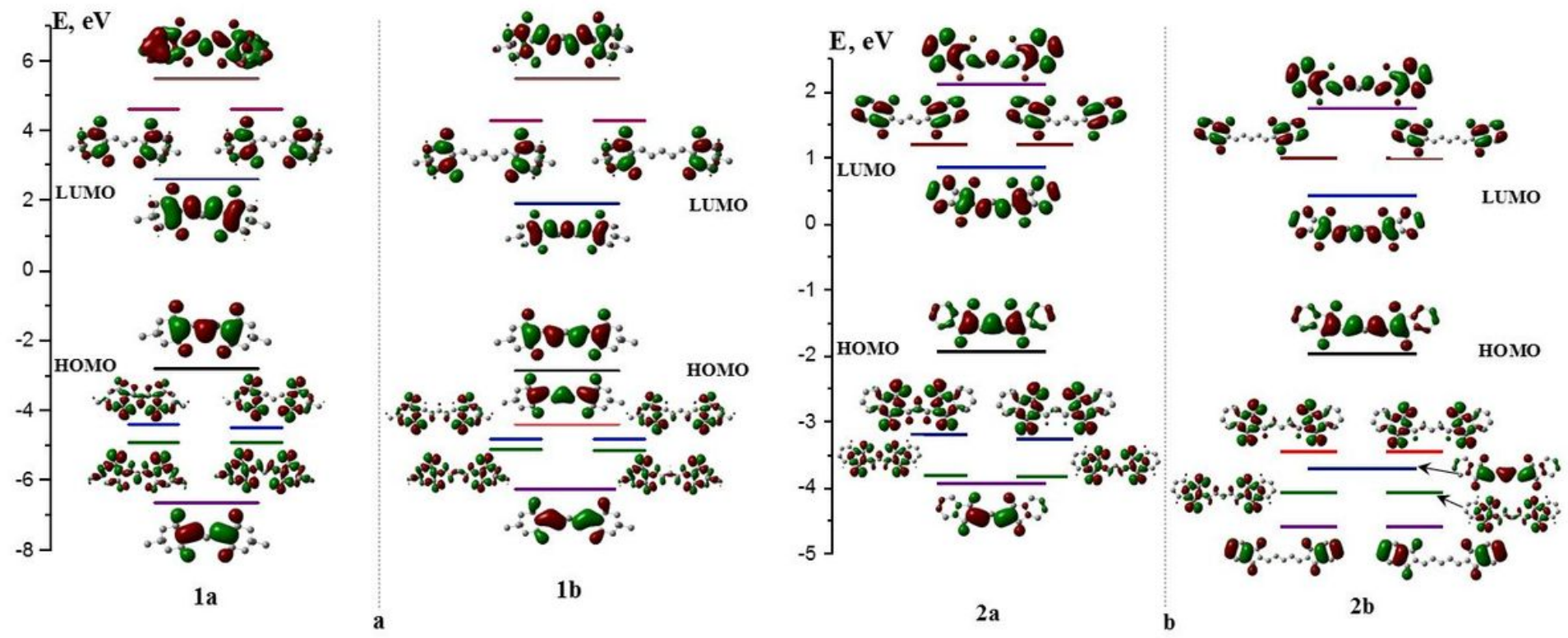

Figure 4

Energies and shape of frontier and nearest MOs in 1a,b (a) and 2a,b (b).
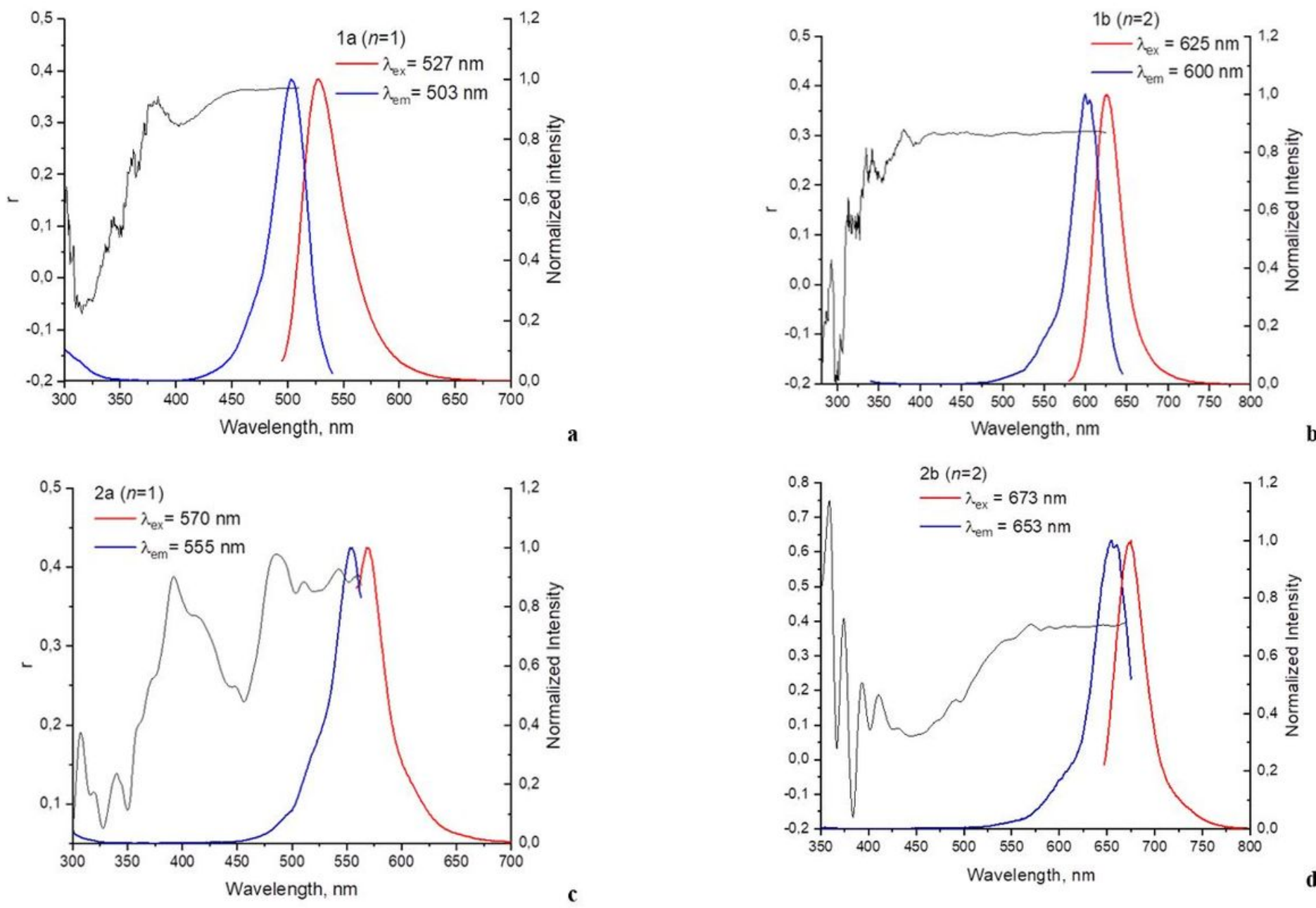

Figure 5 
Spectra of absorption (blue) fluorescence (red) and fluorescence excitation anisotropy (black) of the dyes $1 a(a), 1 b(b), 2 a(c), 2 b(d)$. 